\title{
Posttraumatic Stress Disorder Mediated by Exposure Level in French Civil Firefighters Following a Terrorist Attack: Some Hypotheses towards a Structural Model
}

\author{
Angelika Wolman ${ }^{*}$, Jean-Marie Stève ${ }^{2,3}$, Marion Samor ${ }^{4}$, Evelyne Bouteyre ${ }^{5}$, \\ Themistoklis Apostolidis ${ }^{6}$, Abdessadek El Ahmadi ${ }^{*}$ \\ ${ }^{1}$ Aix-Marseille University, CNRS, LNSC UMR7260, Marseille, France \\ ${ }^{2}$ Service Départemental d'Incendie et de Secours (SDIS 06), Nice, France \\ ${ }^{3}$ Ecole Nationale Supérieure des Officiers de Sapeurs-Pompiers (ENSOSP), Aix-en-Provence, France \\ ${ }^{4}$ Service Départemental d'Incendie et de Secours (SDIS 11), Carcassonne, France \\ ${ }^{5}$ Aix-Marseille University, LPCPP, Aix-en-Provence, France \\ ${ }^{6}$ Aix-Marseille University, LPS, Aix-en-Provence, France \\ Email: ^rwolman@hotmail.de, ^abdessadek.el-ahmadi@univ-amu.fr
}

How to cite this paper: Wolman, A., Stève, J.-M., Samor, M., Bouteyre, E., Apostolidis, T. and El Ahmadi, A. (2020) Posttraumatic Stress Disorder Mediated by Exposure Level in French Civil Firefighters Following a Terrorist Attack: Some Hypotheses towards a Structural Model. World Journal of Neuroscience, 10, 121-134.

https://doi.org/10.4236/wjns.2020.103014

Received: January 25, 2020

Accepted: August 3, 2020

Published: August 6, 2020

Copyright $\odot 2020$ by author(s) and Scientific Research Publishing Inc. This work is licensed under the Creative Commons Attribution International License (CC BY 4.0).

http://creativecommons.org/licenses/by/4.0/

\begin{abstract}
To date, few studies have investigated the impact of organizational factors such as organizational status or the rank of firefighters on the development of posttraumatic stress disorder (PTSD) following a terrorist attack. To fill this gap in the scientific literature, this field study aimed to investigate the consequences of terrorist attacks on firefighters' psychological health in terms of PTSD. Data were collected in France following two terrorist attacks. PTSD was assessed with the PCL-S (DSM-IV) 3 to 6 months after the events. Confirmatory factor analyses (CFAs) with existing PTSD models were inconclusive, leading us to find a two-factor model via an exploratory factor analysis (EFA). A cluster analysis showed different symptom profiles that were influenced by the exposure level. Elements for a structural model explaining PTSD symptoms are proposed and suggest a central role of the exposure level. Firefighters I/II represented an at-risk sub-population, suggesting that PTSD was mainly experienced among those who performed tasks not common to their occupation.
\end{abstract}

\section{Keywords}

PTSD, Firefighters, Terrorist Attack, Rank, SEM 


\section{Introduction}

Terror attacks have a strong impact on the civil population due to their live threatening character. Victims frequently suffer from memories related to the experience, sometimes long after the event. PTSD is a major disorder that specifically develops subsequently to traumatic contexts that may result from one or several violent exposures to death, death threat, injury or sexual abuse, even when physical health is preserved [1] [2] [3] [4]. PTSD is a psychiatric disorder accompanied by high mental suffering [5] and has devastating effects on the personal and professional lives of those affected. The question we address here is how first responders handle terrorist attacks when intervening professionally. Do they resist traumatic aftermaths following an intervention as part of their job?

One major factor to consider when studying rescue workers is occupational status. A firefighter is either a career firefighter or a volunteer. Both groups engage in similar activities, although there are some important differences that require special mention. For example, volunteers usually have a separate paid job. Consequently, the duration of exposure to potentially traumatic events differs. Moreover, volunteers are subjected to higher demands regarding coordination between work, family and volunteer work. Differences concerning the geographical areas that are served are noteworthy: volunteers are deployed in rural districts, while professionals often work in more densely populated areas. Organizational factors, such as a more systematic recruitment process, are more relevant to career firefighters than volunteers. These contrasts in occupational status (professional vs. volunteer) "create stress vulnerabilities that contribute to the development and/or exacerbation of psychiatric conditions" [6] and seem important in the development of existing psychiatric symptoms. Indeed, findings have suggested that volunteer firefighters report more psychiatric symptoms compared to career firefighters. This may be explained by greater structural barriers to mental health treatment for the volunteer firefighters (e.g. cost, availability of resources; Stanley et al. [6], see also Kim et al. [7]). Absenteeism and early retirement are common phenomena among first responders with PTSD [8], and victims are more likely to quit their jobs when they present symptoms [9]. It should be noted that in France, approximately $90 \%$ of firefighters are volunteers. We hypothesize higher PTSD expression in volunteers than in professional firefighters.

The prevalence of PTSD varies across cultural groups due to the differential likelihood of experiencing trauma [5]. In rescue workers, the PTSD prevalence varies from $0 \%$ to $46 \%$ [10]. Firefighters show a similar prevalence range from less than $6 \%$ to more than $37 \%$ [11]. These rates indicate a higher prevalence of PTSD in rescue workers than in the general population. Given the elevated prevalence of psychiatric symptoms among firefighters, firefighter-specific characteristics that may potentiate the risk of developing these disorders are of interest. Therefore, specific at-risk sub-populations were identified. Indeed, the identification of "those individuals within the fire service who are at a higher risk for 
specific occupational injury/illness/disease" [12] is listed among the priorities in terms of research identified by the 2015 National Fire Service Research Agenda. Therefore, we will examine exposure level and PTSD in regard to occupational status and rank. These variables were examined in some previous studies [13] [14], and a positive link between PTSD and the executive ranks (in comparison to the organizational ranks, such as officers) was found.

In this study, we examined the psychological impact in terms of PTSD in firefighters who were active in the rescue interventions in two terrorist attacks. One attack took place on Bastille Day, 23 July 2016, in Nice, France, and resulted in approximately 80 civilian deaths and more people injured by a truck. The second attack occurred in Carcassonne, France, on 23 March 2018, where a terrorist threatened civilians in a supermarket. A policeman offered himself as a hostage to have another victim released. Finally, the policeman was killed. Data were gathered from all firefighters to better elucidate the impact of exposure level on PTSD symptomatology in association with the subject's position (rank and status) in the fire service centre.

The study was approved by the Health and Safety and Working Conditions Committee (Comité d'Hygiène et de Sécurité et des Conditions de Travail), responsible for promoting actions aimed at preserving the physical and mental health of employees. Furthermore, we respected the ethics code of the American Psychological Association [15] and the ethics code of French psychologists [16]. The consent has been organized by the firefighter department hierarchy (Dr. Jean-Marie Stève, co-author). The recruitment into the study was based on voluntary participation.

\section{Method}

\subsection{Participants}

The participants were civil French firefighters who were involved in either the French Bastille Day attack on 14 July 2016 in Nice (respondent age: $\mathrm{M}=42.35$, $\mathrm{SD}=9.93$; non-respondent age: $\mathrm{M}=37.8, \mathrm{SD}=9.55)$ or in the terrorist attack on 23 March 2018 in Carcassonne (age: $M=41.31, \mathrm{SD}=9.83$ ). The participants' demographic data are depicted in Table 1 . A total of 186 out of 490 fire service staff involved in these events completed the Posttraumatic CheckList Scale (PCL-S; Weathers et al. [17]).

\subsection{Procedure}

Following the terrorist attacks, the PCL-S was sent to firefighters involved in the rescue operation. The questionnaires were sent in paper form and were also available online. The free return of the questionnaires was offered via an internal system of the firefighters' departments. In Nice, the data were mainly obtained approximately 6 months, with some late responses through 21 months, after the terrorist attack $(\mathrm{N}=117)$. In Carcassonne $(\mathrm{N}=69)$, these measures were taken 3 months after the attack. Most of the responses were collected at 3 and 6 months. 
Table 1. Demographic variables of respondents and non-respondents in Nice and respondents in Carcassonne.

\begin{tabular}{|c|c|c|c|c|c|c|}
\hline & \multicolumn{2}{|c|}{$\begin{array}{l}\text { Nice: Respondents } \\
\qquad(\mathrm{N}=117)\end{array}$} & \multicolumn{2}{|c|}{$\begin{array}{l}\text { Nice: Non-Respondents } \\
\qquad(\mathrm{N}=304)\end{array}$} & \multicolumn{2}{|c|}{$\begin{array}{l}\text { Carcassonne } \\
\qquad(\mathrm{N}=69)\end{array}$} \\
\hline & $\mathrm{N}$ & $\%$ & $\mathrm{~N}$ & $\%$ & $\mathrm{~N}$ & $\%$ \\
\hline \multicolumn{7}{|l|}{ Gender } \\
\hline Men & 107 & 27.6 & 281 & 72.4 & 55 & 85.9 \\
\hline Woman & 7 & 23.3 & 23 & 76.7 & 9 & 14.1 \\
\hline \multicolumn{7}{|l|}{ Occupational status } \\
\hline Volunteer & 35 & 21.3 & 129 & 78.7 & 30 & 55.6 \\
\hline Professional & 60 & 27.0 & 162 & 73.0 & 24 & 44.4 \\
\hline Administration & 7 & 35.0 & 13 & 65.0 & 0 & 0 \\
\hline \multicolumn{7}{|l|}{ Rank } \\
\hline Firefighter I, II & 22 & 19.8 & 89 & 80.2 & 6 & 10.9 \\
\hline Non-commissioned officers & 41 & 23.7 & 132 & 76.3 & 23 & 41.8 \\
\hline Officers & 24 & 37.5 & 40 & 62.5 & 17 & 30.9 \\
\hline Physician, nurse & 9 & 23.1 & 30 & 76.9 & 9 & 16.4 \\
\hline Pharmacist & 2 & 100 & 0 & 0 & 0 & 0 \\
\hline Administration & 7 & 100 & 0 & 0 & 0 & 0 \\
\hline \multicolumn{7}{|l|}{ Marital status } \\
\hline Married, civil partnership, free love & 61 & 25.1 & 182 & 74.9 & & \\
\hline Divorced, living separated & 13 & 50.5 & 13 & 50.0 & & \\
\hline Single & 20 & 15.6 & 108 & 84.4 & & \\
\hline Widower & 1 & 50.0 & 1 & 50.0 & & \\
\hline
\end{tabular}

Note: We did not indicate missing data and their percentages for each variable.

\subsection{Measures}

\subsubsection{Posttraumatic Check List Scale (PCL-S)}

The PCL-S is a widely used, self-reported 17-item questionnaire for evaluating the severity of PTSD symptoms. It was developed by Weather et al. ([17]; French translation by Ventureyra et al. [18]) and followed the DSM-IV classification. The respondents rated on a 5-point Likert scale from 1 (=not at all) to 5 (=extremely) the extent to which they had experienced symptoms in the past month. The participants were instructed to respond to the PCL-S items in relation to the terrorist attack. For screening purposes, this questionnaire seemed adequate, all the more since the DSM-IV version of PCL-S has been shown to detect a slightly higher number of individuals with PTSD than does the DSM-V classification [19].

Paul et al. [20] assessed two cut-off scores (34 and 44) in a military sample, one for screening and the second for diagnostic purposes. For the higher score, a sensitivity of $80 \%$ and a specificity of $95 \%$ were established. The most discrimi- 
nating threshold for separating subjects with and without follow-up indications of PTSD was 34 , with a sensitivity of $78 \%$ and a specificity of $94 \%$.

\subsubsection{Exposure Level}

The exposure of each firefighter was judged based on the firefighter's activities (e.g. primary intervention, reinforcement in barracks, absence (i.e. time on holiday)) and intervention time. The judge estimated the exposure level on a scale from 0 to 3 . An exposure level of " $0=$ not involved" was attributed to the firefighters who felt concerned by the event but who were not actively involved. This level was followed by an exposure level of " $1=$ involved outside the field (reinforcement barracks, reception of calls)", " $2=$ involved at the scene of the attack" and " $3=$ very involved on the scene, before, during and after the attack". The mean exposure level was $1.6(\mathrm{SD}=0.84)$ for the Nice respondents and 1.8 $(\mathrm{SD}=0.61)$ for the Carcassonne participants.

\subsubsection{Rank}

The rank represents hierarchical power and involves different duties. The current study distinguished between three ranks. Officers have authority in the hierarchical organization of firefighters. Firefighters I/II are responsible for hands-on actions in rescue or fire suppression interventions. Non-commissioned officers are an intermediate rank; they have some authority duties but also execute hands-on actions. In addition, medical staff (nurse, emergency doctor) and pharmacists constituted two separate groups based on activities (pharmacists surveyed medication availability in the background, while nurses and doctors directly provided first aid in the disaster area).

\subsubsection{Occupational Status}

The present study distinguished between volunteer and career firefighters. A third group involved in the rescue intervention was the administrative staff who acted mainly in the background.

\subsection{Data Analyses}

A confirmatory factor analysis (CFA) was applied when testing the nature of the relations among the latent constructs measured by the 17 items of the questionnaire. We evaluated the model based on different fit indices recommended in the literature [21]. An exploratory factor analysis (EFA) was also used to identify a set of latent factors underlying the 17 items of the questionnaire. Because there was no unique solution in the EFA, we adopted the orthogonal varimax rotation. The advantage of this solution is its simplicity and conceptual clarity. To label the factors, factor loadings less than 0.4 were neglected.

A hierarchical cluster analysis was used to sort firefighters into groups (profiles). The similarity between the individual responses on the 17 items was the squared Euclidian distance.

Last, to study the relationships between several variables (age, exposure level, 
factor scores, occupational rank, occupational status, marital status, etc.), different univariate linear model methods were used, including linear regression analysis, ANOVA and ANCOVA.

All multivariate and univariate analyses were performed using $\mathrm{R}$ [22] and JASP version 0.9 [23] software.

\section{Results}

First, the PTSD prevalence was calculated. Of the Nice respondents, 39 (33.33\%) out of 117 respondents indicated a global score above 34, meeting the screening threshold [20]. Of these, 20 (17.9\%) presented a score above 44, meeting the diagnostic value proposed by Paul et al. [20]. Of the Carcassonne respondents, 3 (4.35\%) people out of 69 had total scores from 34 to 40, and no one scored above 44.

The diversity of the PTSD structural models proposed in the literature expresses the complexity of trauma. We focused on eight models related to the DSM-IV that were tested via a CFA as specified in Table 2. The results showed poor fit with our data (Table 3), which led us to apply an EFA to the PCL-S. The EFAs (Table 4) were based on all responses $(\mathrm{N}=186)$. Two EFAs were processed, one for the Nice data only and one that included the Carcassonne data.

Based on principal component analyses (PCA) and following the Kaiser criterion (eigenvalue $>1$ ), two factors emerged. The first (48\%) and the second (10\%) principal components were submitted to a varimax rotation. The rotated factors were of quasi-equal importance ( $29 \%$ vs. $26 \%$ ). The first factor represented the intrusion, avoidance and hyperstimulation dimension (hereby called the "vigilance" factor), whereas the second factor included the emotion numbing elements of PTSD symptomatology; hereby referred to as the "emotion" factor. This factor structure was invariant with or without the data from Carcassonne. The factor scores were computed (by the regression method) and used in subsequent analyses.

A hierarchical clustering was performed (all 186 observations) to extract different reaction profiles of the firefighters. The hierarchical tree (dendrogram) suggested clustering into three clusters. Figure 1 shows a 2-dimensional representation of this hierarchical tree on the map produced by the first two factors (vigilance and emotion). Individual data points as well as contour lines indicating the density of points are depicted. First class members $(\mathrm{N}=22)$ expressed a high level of symptomatology on both or at least one of the two factors. Class 2 $(\mathrm{N}=100)$ included the majority of firefighters with no symptoms to some symptoms. The third class $(\mathrm{N}=46)$ grouped those individuals who showed some signs, mainly on the vigilance factor.

Crossing the occupational rank and the clusters showed that firefighters I/II were over-represented in the first profile $\left(\chi^{2}(1)=8.24 ; p=0.004\right)$. Precisely, the effect of rank was significant for the vigilance factor $(F(5,153)=2.850 ; p=$ $0.017)$ but not for the emotion factor $(F(5,153)=1.678 ; p=0.143)$. Bonferroni 
Table 2. Specifications of the eight models tested: item mapping for proposed confirmatory factor models.

\begin{tabular}{|c|c|c|c|c|c|c|c|c|}
\hline \multirow{2}{*}{ DSM-IV PTSD symptoms } & \multicolumn{8}{|c|}{ Model } \\
\hline & DSM-IV & King et al. $[24]^{\mathrm{a}}$ & a Elhai et al. [25] & $1^{\mathrm{b}}$ & $2^{\mathrm{b}}$ & $3 b^{b}$ & Dysphoria $^{\mathrm{b}}$ & Rasmussen et al. [26] ${ }^{\mathrm{c}}$ \\
\hline $\begin{array}{l}\text { B1. Recurrent thoughts or memories } \\
\text { of the most hurtful or terrifying } \\
\text { events. }\end{array}$ & $\mathrm{R}$ & $\mathrm{R}$ & $\mathrm{R}$ & $\mathrm{P}$ & $\mathrm{R}, \mathrm{A}$ & $\mathrm{R}, \mathrm{A}$ & $\mathrm{R}$ & AI \\
\hline B2. Recurrent nightmares. & $\mathrm{R}$ & $\mathrm{R}$ & $\mathrm{R}$ & $\mathrm{P}$ & $\mathrm{R}, \mathrm{A}$ & $\mathrm{R}, \mathrm{A}$ & $\mathrm{R}$ & AI \\
\hline $\begin{array}{l}\text { B3. Feeling as though the event is } \\
\text { happening again. }\end{array}$ & $\mathrm{R}$ & $\mathrm{R}$ & $\mathrm{R}$ & $\mathrm{P}$ & $\mathrm{R}, \mathrm{A}$ & $\mathrm{R}, \mathrm{A}$ & $\mathrm{R}$ & $\mathrm{AI}$ \\
\hline $\begin{array}{l}\text { B4. Sudden emotional reaction } \\
\text { when reminded of the most hurtful } \\
\text { or traumatic events. }\end{array}$ & $\mathrm{R}$ & $\mathrm{R}$ & $\mathrm{R}$ & $\mathrm{P}$ & $\mathrm{R}, \mathrm{A}$ & $\mathrm{R}, \mathrm{A}$ & $\mathrm{R}$ & AI \\
\hline $\begin{array}{l}\text { B5. Sudden physical reaction when } \\
\text { reminded of the most hurtful or } \\
\text { traumatic events. }\end{array}$ & $\mathrm{R}$ & $\mathrm{R}$ & $\mathrm{R}$ & $\mathrm{P}$ & $\mathrm{R}, \mathrm{A}$ & $\mathrm{R}, \mathrm{A}$ & $\mathrm{R}$ & AI \\
\hline $\begin{array}{l}\text { C1. Avoiding activities that remind } \\
\text { you of the traumatic or hurtful event. }\end{array}$ & $\mathrm{A} / \mathrm{N}$ & A & A & $\mathrm{P}$ & $\mathrm{R}, \mathrm{A}$ & $\mathrm{R}, \mathrm{A}$ & $\mathrm{A}$ & A \\
\hline $\begin{array}{l}\text { C2. Avoiding thoughts or feelings } \\
\text { associated with the traumatic or } \\
\text { hurtful event. }\end{array}$ & $\mathrm{A} / \mathrm{N}$ & A & $\mathrm{A}$ & $\mathrm{P}$ & $\mathrm{R}, \mathrm{A}$ & $\mathrm{R}, \mathrm{A}$ & A & A \\
\hline $\begin{array}{l}\text { C3. Inability to remember parts of } \\
\text { the most traumatic or hurtful events. }\end{array}$ & $\mathrm{A} / \mathrm{N}$ & $\mathrm{N}$ & $\mathrm{N}$ & $\mathrm{P}$ & $\mathrm{R}, \mathrm{A}$ & $\mathrm{N}$ & $\mathrm{D}$ & $\mathrm{N}$ \\
\hline C4. Less interest in daily activities. & $\mathrm{A} / \mathrm{N}$ & $\mathrm{N}$ & $\mathrm{N}$ & $\mathrm{P}$ & $\mathrm{H}, \mathrm{N}$ & $\mathrm{N}$ & $\mathrm{D}$ & $\mathrm{N}$ \\
\hline $\begin{array}{l}\text { C5. Feeling detached or withdrawn } \\
\text { from people. }\end{array}$ & $\mathrm{A} / \mathrm{N}$ & $\mathrm{N}$ & $\mathrm{N}$ & $\mathrm{P}$ & $\mathrm{H}, \mathrm{N}$ & $\mathrm{N}$ & $\mathrm{D}$ & $\mathrm{N}$ \\
\hline C6. Unable to feel emotions. & $\mathrm{A} / \mathrm{N}$ & $\mathrm{N}$ & $\mathrm{N}$ & $\mathrm{P}$ & $\mathrm{H}, \mathrm{N}$ & $\mathrm{N}$ & $\mathrm{D}$ & $\mathrm{N}$ \\
\hline $\begin{array}{l}\text { C7. Feeling as if you don't have } \\
\text { a future. }\end{array}$ & $\mathrm{A} / \mathrm{N}$ & $\mathrm{N}$ & $\mathrm{N}$ & $\mathrm{P}$ & $\mathrm{H}, \mathrm{N}$ & $\mathrm{N}$ & $\mathrm{D}$ & $\mathrm{N}$ \\
\hline D1. Trouble sleeping. & $\mathrm{H}$ & $\mathrm{H}$ & DA & $\mathrm{P}$ & $\mathrm{H}, \mathrm{N}$ & $\mathrm{H}$ & $\mathrm{D}$ & AI \\
\hline $\begin{array}{l}\text { D2. Feeling irritable or having } \\
\text { outbursts of anger. }\end{array}$ & $\mathrm{H}$ & $\mathrm{H}$ & DA & $\mathrm{P}$ & $\mathrm{H}, \mathrm{N}$ & $\mathrm{H}$ & $\mathrm{D}$ & $\mathrm{H}$ \\
\hline D3. Difficulty concentrating. & $\mathrm{H}$ & $\mathrm{H}$ & DA & $\mathrm{P}$ & $\mathrm{H}, \mathrm{N}$ & $\mathrm{H}$ & $\mathrm{D}$ & AI \\
\hline D4. Feeling on guard. & $\mathrm{H}$ & $\mathrm{H}$ & AA & $\mathrm{P}$ & $\mathrm{H}, \mathrm{N}$ & $\mathrm{H}$ & $\mathrm{H}$ & $\mathrm{H}$ \\
\hline D5. Feeling jumpy, easily startled. & $\mathrm{H}$ & $\mathrm{H}$ & AA & $\mathrm{P}$ & $\mathrm{H}, \mathrm{N}$ & $\mathrm{H}$ & $\mathrm{H}$ & $\mathrm{H}$ \\
\hline
\end{tabular}

Note: R, reexperiencing; A, avoidance; N, numbing; H, hyperarousal; D, dysphoria; DA, dysphoric arousal; AA, anxious arousal, AI, aroused intrusion, C, physiology and cognition. ${ }^{\mathrm{a} K i n g}$ et al. [24]. ${ }^{\mathrm{b}}$ Simms et al. [27]. ${ }^{\mathrm{C}}$ Rasmussen et al. [26].

Table 3. Fit indices for the eight tested models.

\begin{tabular}{cccccccc}
\hline Model & $X^{2}$ & $d f$ & $p$ & GFI & CFI & RMSEA & AIC \\
\hline American Psychiatric Association [28] & 461.6445 & 116 & 0.000 & 0.767 & 0.812 & 0.127 & 535.6445 \\
King et al. [24] & 311.9062 & 113 & 0.000 & 0.847 & 0.891 & 0.098 & 391.906 \\
Elhai et al. [25] & 298.3461 & 109 & 0.000 & 0.850 & 0.896 & 0.097 & 386.3461 \\
Rasmussen et al. [26] & 297.5763 & 109 & 0.000 & 0.851 & 0.897 & 0.097 & 385.5763 \\
$1^{\text {a }}$ & 572.4713 & 119 & 0.000 & 0.697 & 0.752 & 0.144 & 640.4713 \\
$2^{\text {a }}$ & 445.3951 & 118 & 0.000 & 0.771 & 0.821 & 0.123 & 515.3951 \\
3b $^{\mathrm{a}}$ & 338.6681 & 116 & 0.000 & 0.833 & 0.878 & 0.102 & 412.6681 \\
Dysphoria $^{\mathrm{a}}$ & 380.451 & 113 & 0.000 & 0.899 & 0.854 & 0.114 & 460.451 \\
\hline
\end{tabular}

Note: $X^{2}$ goodness of fit statistics with its degrees of freedom and $p$ value; GFI = Goodness of Fit Index; CFI = Bentler's Comparative Fit Index; RMSEA =

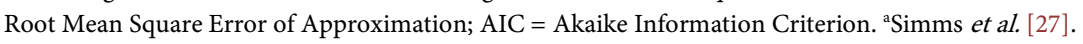


Table 4. Item saturations of the two factors after varimax rotation.

\begin{tabular}{lcccc}
\hline & \multicolumn{2}{c}{ Carcassonne + Nice } & \multicolumn{2}{c}{ Nice } \\
\cline { 2 - 5 } & Vigilance & Emotion & Vigilance & Emotion \\
\hline 1) Intrusive thoughts & 0.755 & & 0.766 & \\
2) Distressing dreams & 0.700 & & 0.709 & \\
3) Flashbacks & 0.682 & & 0.680 & \\
4) Upset by reminders & 0.708 & & 0.692 & \\
5) Physical reactions to reminders & 0.471 & 0.430 & 0.511 & 0.440 \\
6) Avoidance of thoughts & 0.609 & & 0.578 & \\
7) Avoidance of reminders & 0.746 & & 0.724 & \\
8) Psychogenic amnesia & & 0.428 & & 0.417 \\
9) Anhedonia & & 0.708 & & 0.717 \\
10) Estrangement of others & & 0.817 & & 0.838 \\
11) Psychic numbing & & 0.864 & & 0.885 \\
12) Foreshortened future & & 0.660 & & 0.666 \\
13) Sleep difficulties & 0.522 & 0.470 & 0.498 & 0.479 \\
14) Irritability/anger & 0.546 & 0.549 & 0.512 & 0.587 \\
15) Impaired concentration & & 0.589 & & 0.610 \\
16) Hypervigilance & 0.530 & & 0.521 & \\
17) Exaggerated startle & 0.465 & 0.548 & 0.476 & 0.545 \\
\hline
\end{tabular}

Note: Principal component analysis, varimax rotation. Saturations below 0.40 are not considered. All four factors: Cronbach's $\alpha=0.90$.

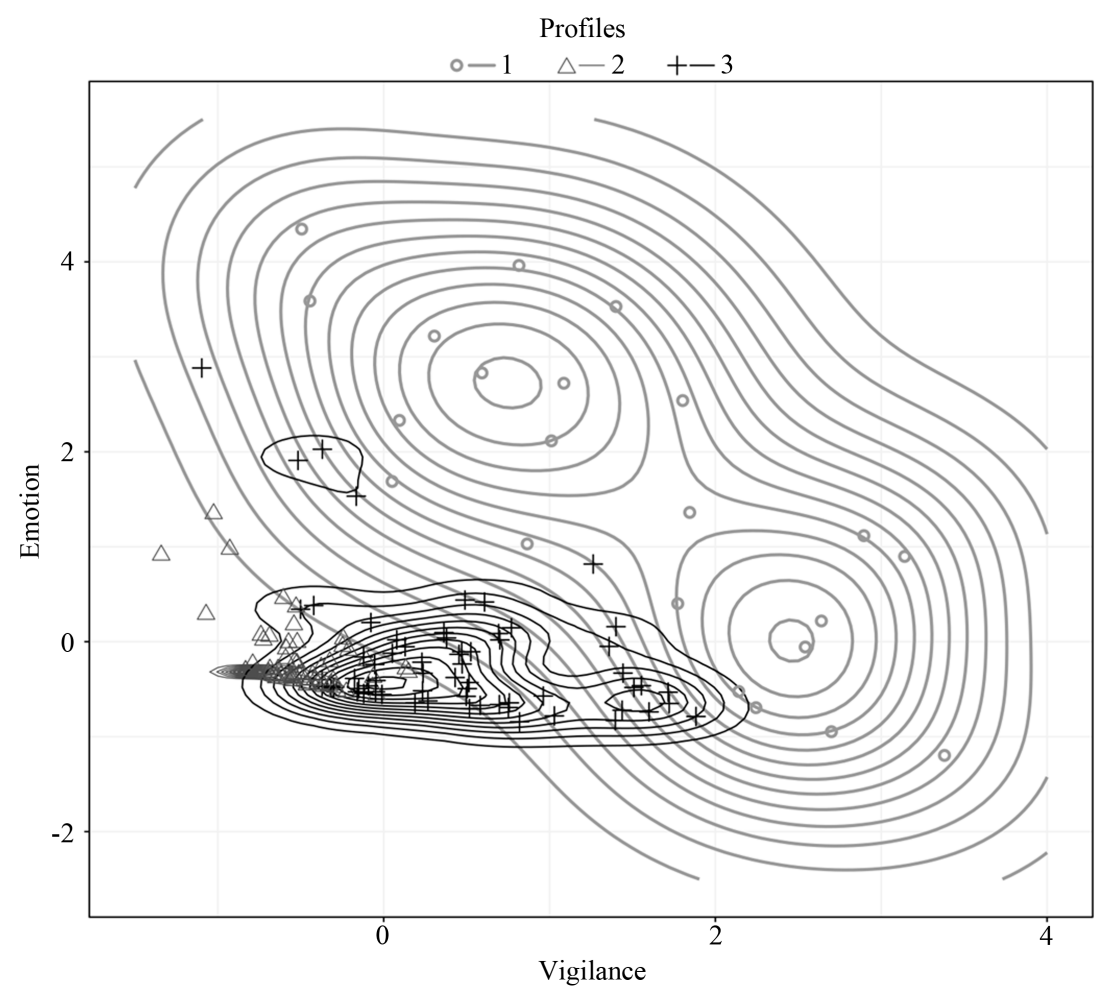

Figure 1. Three clusters representing the respondent profiles. 
post hoc analyses showed that firefighters I/II presented higher scores on vigilance than did officers $(t(153)=2.513 p=0.013)$ and medical staff $(t(153)=$ $2.683 ; p=0.008)$. No differences existed between the rank positions for the emotion factor $(F(5,153)=1.498, p=0.193)$. Second, crossing the occupational status and the clusters indicated an independence of both variables $\left(\chi^{2}(4)=3.24, p\right.$ $=0.519)$, indicating that status seems to have no impact on the three symptom profiles.

A question arose about the impact of the exposure level of the firefighters in these profiles. An ANOVA on the link between the three profiles and the exposure level was highly significant $(F(2,180)=5.282 ; p=0.006)$. Simple correlations between the exposure level and the two factors, vigilance and emotion, are listed in Table 5. Based on these simple correlations, the vigilance factor also seemed dependent on age, which played a protective role (negative correlation), and on the exposure level, which decreased symptoms of vigilance. The second factor, emotion, seemed to depend only on the exposure level. In return, the exposure level was influenced by rank $(F(5,153)=6,293 ; p<0.001)$ and status $(F(2,149)=7.211 ; p=0.001)$. The significance found for status is due to the administrative staff whose exposure level was naturally very low compared to the volunteer and career firefighters (contrast: $p<0.001$ ). No significant differences (contrast: $p=0.348$ ) were found between the latter.

These results highlighted only simple effects. The results can be summarized in a network of mediations and/or modulations as depicted in Graph 1. Given the lack of strong theoretical models, we limited ourselves to exploratory models and the proposition of hypotheses. These mediational hypothesises are summarized in a schematic model in which the two factors, vigilance and emotion, play the role of dependent variables and the exposure level is a mediating variable.

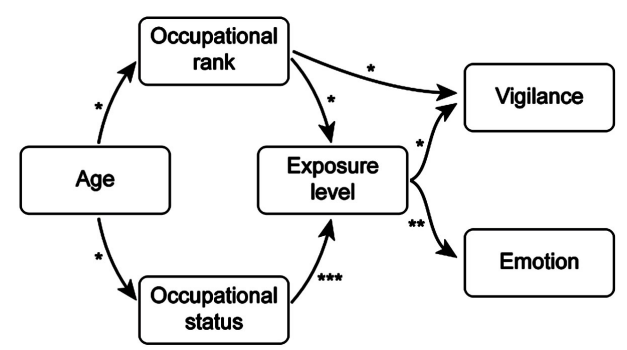

Graph 1. Schematic diagram of the effects that revealed significance via different analyses. Note: ${ }^{*} p \leq 0.05 .{ }^{* *} p \leq 0.01 .{ }^{* * *} p \leq 0.001$. Analyses: linear regression, ANOVA, and ANCOVA.

Table 5. Pearson's simple correlations of quantitative variables.

\begin{tabular}{cccccc}
\hline & Variable & 1 & 2 & 3 & 4 \\
\hline 1$)$ & Vigilance & - & 0.121 & $-0.138\left(^{*}\right)$ & $0.151^{\star}$ \\
$2)$ & Emotion & & - & -0.074 & $0.229^{* *}$ \\
$3)$ & Age & & & - & -0.099 \\
$4)$ & Exposure level & & & & - \\
\hline
\end{tabular}

Note. $\left(^{*}\right) p \leq 0.10 ;{ }^{*} p \leq 0.05 ;{ }^{* *} p \leq 0.01$. 


\section{Discussion}

The present study is one of the few investigations of PTSD expression in firefighters as a result of specific traumatic events. Here, we highlight and discuss the main findings. First, the schematic model depicted in graph 1 is discussed. Then, before addressing the meaning of the two factors of vigilance and emotion, we briefly situate the PTSD prevalence in the context of first responders.

In accordance with the literature, the exposure level was the main factor explaining PTSD symptoms in firefighters. For example, Paul et al. [20] highlighted a proportional relationship between PTSD severity and the exposure level to traumatic events. Similarly, Vandentorren et al. [29] observed a positive relationship between the exposure level and the severity of symptomatology on victims, rescuers and witnesses after terrorist attacks in Paris in 2015.

Rank emerged as a risk factor in our study. Even though firefighters I/II and medical staff presented the same exposure level, the former expressed more symptoms than the latter. We can only hypothesize that this may be due to the type of activities in which the rescuers engaged. Firefighters join the service with the notion of defeating fires. In contrast, a terrorist attack involves the death of many people and the rescue of many injured civilians under the persistent danger of new attacks during the rescue operation. Therefore, we hypothesize that firefighters, compared to medical staff, were not engaging in their main responsibility. As proposed by Perrin et al. [30], "the prevalence of PTSD was significantly higher among those who performed tasks not common for their occupation" [30].

Stanley et al. [6] report significantly elevated symptoms of posttraumatic stress in volunteers compared to career firefighters. We found independence between the occupational status and symptomatology. This difference in findings may be explained by the fact that we investigated PTSD symptoms in response to a specific event, whereas Stanley et al. [6] compared symptoms between firefighters in volunteer-only and career-only departments.

Nevertheless, occupational status influenced the exposure level, suggesting that administrative staff and volunteer/professional firefighters were not exposed to the same level. This is not surprising as the administrative service acts in the background and the volunteers and professionals were directly at the location of the terrorist attack.

Age is a factor with a contradictory impact on PTSD in the literature. Bressler et al. [4] considered young age a risk factor in the development of PTSD. It is noteworthy that their meta-analysis is not specific to first responders. In a rescue worker sample, Paul et al. [20] report the absence of a direct effect of age on PTSD. In our population of first responders, the effect of age on the development of traumatic stress symptoms is mediated by organizational factors such as rank.

The PTSD prevalence rates assessed in the Nice and Carcassonne groups were as widespread as in the literature [31]. The group-related differences in the prevalence rate found in our investigation may be due to the type of disaster, location and moment of data collection (here considered confounding variables). 
Posttraumatic stress symptoms were related to two main factors. In the literature, the PTSD factor structure has varied considerably between one and five factors [4] [24] [27], with a majority of the models containing four factors [32]. All confirmatory models we tested (based on Elhai et al. [25] and Simms et al. [27]) showed unsatisfactory results in our sample. Therefore, we extracted a two-factor model invariant for the Carcassonne and the Nice populations. Our first "vigilance" factor included intrusive thoughts and flashbacks, avoidance behaviour and hyperstimulation symptoms, whereas the second factor, "emotion", grouped anhedonia, estrangement of others and psychic numbing items. Horowitz [33] initially proposed a two-factor model that distinguished intrusive from avoidance states. Subsequently, Taylor et al. [34] found that intrusion and avoidance symptoms loaded together on a first factor and numbing and arousal symptoms loaded together on a second factor [35]. The hierarchical cluster analysis suggested clustering into three profiles depending on symptom expression and therefore provided an interesting indicator of how firefighters cope with this type of event.

Several limitations regarding our data can be noted. First, we had a small sample and missing values on certain variables. The low response rate among firefighters may be due to the paper-based methodology, rank barriers or stigmatization as mental symptomatology may be considered a weakness in firefighters' culture [7] [36]. Furthermore, the psychiatric antecedents of the participants were unknown, as was the medical and psychological care that they may have individually sought after the attack. Moreover, the type of attack (Nice or Carcassonne) and the time of assessment were confounding variables.

The aim of this article was to shed light on rarely considered factors in the development of PTSD in firefighters. We accentuated rank and status as two organizational factors that impact the everyday life of firefighters. We want to encourage further research to validate our findings and to elucidate the factors, psychological, organizational or social, that put firefighters I/II at special risk. We encourage health professionals to determine the needs of firefighter populations in terms of special training and care as firefighters are confronted with traumatic situations every working day. Furthermore, the leading authorities in the rescue workers' barracks should pay specific attention when sending personnel to a rescue intervention.

\section{Acknowledgements}

The authors would like to acknowledge the Ecole Nationale Supérieure des Officiers de Sapeurs-Pompiers [National School for Firefighter Officers].

\section{Conflicts of Interest}

The authors declare no conflicts of interest regarding the publication of this paper.

\section{References}

[1] Bressler, R., Erford, B.T. and Dean, S. (2018) A Systematic Review of the Posttraumat- 
ic Stress Disorder Checklist (PCL). Journal of Counseling \& Development, 96, 167-186. https://doi.org/10.1002/jcad.12190

[2] Berninger, A., Webber, M.P., Cohen, H.W., Gustave, J., Lee, R., Niles, J.K., et al. (2010) Trends of Elevated PTSD Risk in Firefighters Exposed to the World Trade Center Disaster: 2001-2005. Public Health Reports, 125, 556-566. https://doi.org/10.1177/003335491012500411

[3] Galea, S., Nandi, A. and Vlahov, D. (2005) The Epidemiology of Post-Traumatic Stress Disorder after Disasters. Epidemiologic Reviews, 27, 78-91. https://doi.org/10.1093/epirev/mxi003

[4] Madianos, M.G., Papaghelis, M., Ioannovich, J. and Dafni, R. (2001) Psychiatric Disorders in Burn Patients: A Follow-Up Study. Psychotherapy and Psychosomatics, 70, 30-37. https://doi.org/10.1159/000056222

[5] American Psychiatric Association (2013) Diagnostic and Statistical Manual of Mental Disorders. 5th Edition, American Psychiatric Association, Virginia. https://doi.org/10.1176/appi.books.9780890425596

[6] Stanley, I.H., Boffa, J.W., Hom, M.A., Kimbrel, N.A. and Joiner, T.E. (2017) Differences in Psychiatric Symptoms and Barriers to Mental Health Care between Volunteer and Career Firefighters. Psychiatry Research, 247, 236-242. https://doi.org/10.1016/j.psychres.2016.11.037

[7] Kim, J.E., Dager, S.R., Jeong, H.S., Ma, J., Park, S., Kim, J., et al. (2018) Firefighters, Posttraumatic Stress Disorder, and Barriers to Treatment: Results from a Nationwide Total Population Survey. PLoS ONE, 13, e0190630.

https://doi.org/10.1371/journal.pone.0190630

[8] Emsley, R.A., Seedat, S. and Stein, D.J. (2003) Posttraumatic Stress Disorder and Occupational Disability in South African Security Force Members. The Journal of Nervous and Mental Disease, 191, 237-241. https://doi.org/10.1097/01.NMD.0000061882.71610.D9

[9] Koniarek, J. and Dudek, B. (2001) Post-Traumatic Stress Disorder and Fire Fighters Attitude to Their Job. Medycyna Pracy, 52, 177-183.

[10] Berger, W., Coutinho, E.S.F., Figueira, I., Marques-Portella, C., Luz, M.P., Neylan, T.C., et al. (2012) Rescuers at Risk: A Systematic Review and Meta-Regression Analysis of the Worldwide Current Prevalence and Correlates of PTSD in Rescue Workers. Social Psychiatry and Psychiatric Epidemiology, 47, 1001-1011. https://doi.org/10.1007/s00127-011-0408-2

[11] Del Ben, K.S., Scotti, J.R., Chen, Y.-C. and Fortson, B.L. (2006) Prevalence of Posttraumatic Stress Disorder Symptoms in Firefighters. Work \& Stress, 20, 37-48. https://doi.org/10.1080/02678370600679512

[12] National Fallen Firefighters Foundation (2016) 2015 National Fire Services Research Agenda Recommendations Report. NVFC, Greenbelt, US.

[13] Rona, R.J., Hooper, R., Jones, M., Iversen, A.C., Hull, L., Murphy, D., et al. (2009) The Contribution of Prior Psychological Symptoms and Combat Exposure to Post Iraq Deployment Mental Health in the UK Military. Journal of Traumatic Stress, 22, 11-19. https://doi.org/10.1002/jts.20383

[14] Xue, C., Ge, Y., Tang, B., Liu, Y., Kang, P., Wang, M. and Zhang, L.L. (2015) A Meta-Analysis of Risk Factors for Combat-Related PTSD among Military Personnel and Veterans. PLOS ONE, 10, e0120270.

https://doi.org/10.1371/journal.pone.0120270

[15] American Psychological Association (2002) Ethical Principles of Psychologists and 
Code of Conduct. American Psychologist, 57, 1060-1073. https://doi.org/10.1037/0003-066X.57.12.1060

[16] Code de Déontologie des Psychologues (2012) Le Respect de la Personne dans Sa Dimension Psychique Est un Droit Inaliénable. Sa Reconnaissance Fonde L'action des Psychologues. [Code of Ethics of Psychologists [Respect for the Person in His Psychic Dimension Is an Inalienable Right. His Recognition Is the Basis of the Work of Psychologists]. http://www.codededeontologiedespsychologues.fr/

[17] Weathers, F.W., Litz, B.T., Herman, D.S., Huska, J.A. and Keane, T.M. (1993) The PTSD Checklist (PCL): Reliability, Validity, and Diagnostic Utility. Vol. 462, 9 th Annual Conference of the ISTSS, San Antonio, TX.

https://scholar.google.com/citations?user=ddEs-1oAAAAJ\&hl=en\#d=gs_md_cita-d \&u=\%2Fcitations\%3Fview_op\%3Dview_citation\%26hl\%3Den\%26user\%3DddEs-1o AAAAJ\%26citation_for_view\%3DddEs-1oAAAAJ\%3Au-x6o8ySG0sC\%26tzom\%3 $\underline{\mathrm{D}-120}$

[18] Ventureyra, V.A.G., Yao, S.-N., Cottraux, J., Note, I. and De Mey-Guillard, C. (2002) The Validation of the Posttraumatic Stress Disorder Checklist Scale in Posttraumatic Stress Disorder and Nonclinical Subjects. Psychotherapy and Psychosomatics, 71, 47-53. https://doi.org/10.1159/000049343

[19] Kilpatrick, D.G., Resnick, H.S., Milanak, M.E., Miller, M.W., Keyes, K.M. and Friedman, M.J. (2013) National Estimates of Exposure to Traumatic Events and PTSD Prevalence Using DSM-IV and DSM-5 Criteria. Journal of Traumatic Stress, 26, 537-547. https://doi.org/10.1002/jts.21848

[20] Paul, F., De Santi, V.P., Marimoutou, C. and Deparis, X. (2013) Le dépistage: Validation de L'Echelle PCLS et D'un Auto-Questionnaire Court dans le Cadre du Dépistage des États de Stress Post-Traumatiques (ESPT) Chez les Militaires de Retour de Mission. La Psychiatrie en Milieu Militaire [Screening: Validation of the PCLS Scale and of a Short Self-Questionnaire in the Context of Screening for Post-Traumatic Stress Disorder (PTSD) in Soldiers Returning from Mission. In Psychiatry in a Military Environment], Elsevier Masson, Toulon.

[21] Jackson, D.L., Gillaspy, J.A. and Purc-Stephenson, R. (2009) Reporting Practices in Confirmatory Factor Analysis: An Overview and Some Recommendations. Psychological Methods, 14, 6-23. https://doi.org/10.1037/a0014694

[22] The R Development Core Team (2008) R: A Language and Environment for Statistical Computing. R Foundation for Statistical Computing, Vienna, Austria.

[23] JASP Team (2018) JASP (Version 0.9).

[24] King, D.W., Leskin, G.A., King, L.A. and Weathers, F.W. (1998) Confirmatory Factor Analysis of the Clinician-Administered PTSD Scale: Evidence for the Dimensionality of Posttraumatic Stress Disorder. Psychological Assessment, 10, 90-96. https://doi.org/10.1037/1040-3590.10.2.90

[25] Elhai, J.D., Biehn, T.L., Armour, C., Klopper, J.J., Frueh, B.C. and Palmieri, P.A. (2011) Evidence for a Unique PTSD Construct Represented by PTSD's D1-D3 Symptoms. Journal of Anxiety Disorders, 25, 340-345.

https://doi.org/10.1016/j.janxdis.2010.10.007

[26] Rasmussen, A., Smith, H. and Keller, A.S. (2007) Factor Structure of PTSD Symptoms among West and Central African Refugees. Journal of Traumatic Stress, 20, 271-280. https://doi.org/10.1002/jts.20208

[27] Simms, L.J., Watson, D. and Doebbelling, B.N. (2002) Confirmatory Factor Analyses of Posttraumatic Stress Symptoms in Deployed and Nondeployed Veterans of the Gulf War. Journal of Abnormal Psychology, 111, 637-647. 
https://doi.org/10.1037/0021-843X.111.4.637

[28] American Psychiatric Association (1994) Diagnostic and Statistical Manual of Mental Disorders. 4th Edition, American Psychiatric Association, Washington DC.

[29] Vandentorren, S., Sanna, A., Aubert, L., Pirard, P., Motreff, Y., Dantchev, N., et al. (2017) Étude de Cohorte Impacts. Première Étape: Juin-Octobre 2015 [Impacts cohortstudy. First Stage: June-October, 2015] Santé Publique France, Saint-Maurice.

[30] Perrin, M.A., DiGrande, L., Wheeler, K., Thorpe, L., Farfel, M. and Brackbill, R. (2007) Differences in PTSD Prevalence and Associated Risk Factors among World Trade Center Disaster Rescue and Recovery Workers. American Journal of Psychiatry, 164, 1385-1394. https://doi.org/10.1176/appi.ajp.2007.06101645

[31] Lowell, A., Suarez-Jimenez, B., Helpman, L., Zhu, X., Durosky, A., Hilburn, A., et al. (2018) 9/11-Related PTSD among Highly Exposed Populations: A Systematic Review 15 Years after the Attack. Psychological Medicine, 48, 537-553. https://doi.org/10.1017/S0033291717002033

[32] Gauci, M.A. and MacDonald, D.A. (2012) Confirmatory Factor Analysis of the Posttraumatic Stress Disorder Checklist. Journal of Aggression, Maltreatment \& Trauma, 21, 321-330. https://doi.org/10.1080/10926771.2012.665429

[33] Horowitz, M.J. (1979) Psychological Response to Serious Life Events. In: Hamilton, V. and Warburton, D.M., Eds., Human Stress and Cognition: An Information Processing Approach, Wiley, New York, 235-263.

[34] Taylor, S., Kuch, K., Koch, W.J., Crockett, D.J. and Passey, G. (1998) The Structure of Posttraumatic Stress Symptoms. Journal of Abnormal Psychology, 107, 154-160. https://doi.org/10.1037/0021-843X.107.1.154

[35] Andrews, L., Joseph, S., Shevlin, M. and Troop, N. (2006) Confirmatory Factor Analysis of Posttraumatic Stress Symptoms in Emergency Personnel: An Examination of Seven Alternative Models. Personality and Individual Differences, 41, 213-224. https://doi.org/10.1016/j.paid.2005.11.034

[36] Goffman, E. and Kihm, A. (1975) Stigmate: Les Usages Sociaux des Handicaps [Stigma: The Social Uses of Disabilities]. Les Éditions de Minuit, Paris. 